\title{
Antibody response to Pseudomonas aeruginosa surface protein antigens in a rat model of chronic lung infection
}

\author{
DOREEN M. G. COCHRANE, M. R. W. BROWN*, H. ANWAR, P. H. WELLERt, K. LAM $\ddagger$ and \\ J.W. COSTERTON $\ddagger$
}

Microbiology Research Group, Pharmaceutical Sciences Institute, Aston University, Aston Triangle, Birmingham B4 7ET, †Institute of Child Health, The Children's Hospital, Ladywood Middleway, Birmingham B16 8ET and $\ddagger$ Department of Biology, The University of Calgary, Canada T2N 1N4

\begin{abstract}
Summary. For an animal model of infection to be useful in immunological studies it is necessary to establish that the surface antigens expressed by bacteria growing in vivo in the experimental infection mimic those expressed by bacteria in the human infection. In this study, chronic infection was induced by inoculating the lungs of rats with agar beads containing mucoid Pseudomonas aéruginosa. P. aeruginosa was obtained from the lungs 14 days after infection and studied without subculture. Several high-mol.-wt proteins were expressed in the outer membranes (OM) of the bacteria from the rat lungs which could be induced by cultivating the same isolate in iron-depleted conditions in vitro. The pattern of iron-regulated membrane proteins (IRMP) was similar to that obtained in an earlier study with another mucoid isolate of $P$. aeruginosa examined directly, without subculture, from the sputum of a cystic fibrosis patient. Immunoblotting with LPS-absorbed serum from infected rats and also with serum from CF patients showed that IgG in these fluids reacted with the IRMPs and other major OM proteins (OMPs) of $P$. aeruginosa. Antisera from rats immunised with whole cells of $P$. aeruginosa grown in iron-depleted media reacted with all the major OMPs of $P$. aeruginosa, including the IRMPs, confirming their immunogenicity.
\end{abstract}

\section{Introduction}

Pseudomonas aeruginosa infection is commonly associated with progressive pulmonary disease in patients with cystic fibrosis (CF) (Høiby, 1974). Most $P$. aeruginosa isolates from $\mathrm{CF}$ lung infection elaborate an extensive exopolysaccharide at their surface (Doggett et al., 1966) which often is not stable upon culture in vitro. Studies by electronmicroscopy of bronchoscopy and postmortem lung specimens from CF patients infected with $P$. aeruginosa have revealed extensive formation of microcolonies embedded in exopolysaccharide (Lam et al., 1980). In the rat model of $P$. aeruginosa pulmonary infection developed by Cash et al. (1979), chronic infection is achieved by incorporating bacteria in agar beads before intratracheal inoculation into the lung. Bacteria rapidly spread

Received 7 March 1988; revised version accepted 17 May 1988. * Correspondence should be sent to Professor M. R. W. Brown. from these beads and form microcolonies which are widely distributed throughout the bronchioles (Lam et al., 1980). The histopathological changes which occur in the animal lungs resemble those seen in the lungs of CF patients infected with $P$. aeruginosa. The infection is non-invasive; septicaemia and toxaemia do not occur (Costerton, 1984).

Restricting the availability of iron to microorganisms in the body plays an important role in mammalian host defence mechanisms (Weinberg, 1978; Bullen, 1981; Finkelstein et al., 1983; Griffiths, 1983; Weinberg, 1984). The freely available iron in the body fluid is maintained at very low concentrations by the presence of natural ironchelating molecules such as transferrin and lactoferrin which have a high affinity for iron. The bacteria respond to these conditions by synthesising their own iron-scavenging compounds (siderophores) and also by expression of high-mol.-wt, ironregulated membrane proteins (IRMPs) that function as receptors for iron-siderophore complexes 
(Neilands, 1974; Griffiths, 1983). There is considerable evidence to indicate that bacteria grow in iron-restricted conditions in human infections and in experimental animal models of infection. Pathogenic bacteria examined directly, without subculture, from the peritoneum of lethally infected guinea-pigs and from the intact intestinal tracts of infant rabbits contained high-mol.-wt IRMPs(Griffiths et al., 1983; Sciortino and Finkelstein, 1983). $P$ aeruginosa and several other species of gramnegative bacteria grown in situ in human CF lung infection (Anwar et al., 1984; Brown et al., 1984) and urinary-tract infections (Lam et al., 1984; Shand et al., 1985) also expressed IRMPs.

This study was undertaken to explore the similarities between the rat lung model of chronic $P$. aeruginosa pulmonary infection and $P$. aeruginosa infection in the lungs of CF patients. In particular, bacteria isolated directly from the lungs of infected rats were investigated without subculture for expression of IRMPs and an antibody response towards them.

\section{Materials and methods}

\section{Bacterial strain and growth conditions}

Mucoid P. aeruginosa PAO 579 was kindly provided by Dr J. Govan (University of Edinburgh). Strain PAO 579 is a mucoid variant isolated from strain PAO 381 (serotype 5-International Antigenic Typing Scheme); it was cultivated in iron-plentiful tryptone soy broth (TSB + $\mathrm{Fe}$ ) or in iron-depleted tryptone soy broth (TSB-Fe). $\mathrm{TSB}+\mathrm{Fe}$ and $\mathrm{TSB}-\mathrm{Fe}$ were prepared as described previously (Shand et al., 1985; Kadurugamuwa et al., 1987). Litre flasks each containing $250 \mathrm{ml}$ of TSB $+\mathrm{Fe}$ or TSB - Fe were inoculated with $1 \mathrm{ml}$ of an early stationary phase culture of strain PAO 579 grown in TSB $+\mathrm{Fe}$ or $\mathrm{TSB}-\mathrm{Fe}$ respectively. The flasks were shaken in an orbital shaker $(180 \mathrm{rpm})$ at $37^{\circ} \mathrm{C}$. Early stationary phase cells were harvested by centrifugation at $8000 \mathrm{~g}$ for $10 \mathrm{~min}$ and washed once with saline.

\section{Animal model}

The animal model of Cash et al. (1979) was used to induce chronic pulmonary infection in 30 male SpragueDawley rats $(200-250 \mathrm{~g})$. The method of inducing the infection was as reported previously (Lam et al., 1980). Late exponential phase cells of strain PAO 579 grown in $\mathrm{TSB}+\mathrm{Fe}$ were incorporated into agar beads and introduced into the left lobe of rats via a tracheotomy. After 14 days the rats were killed by intramuscular injection of 1-2 $\mathrm{ml}$ of sodium pentobarbital. Blood samples were collected from the rats; serum was separated and stored at $-20^{\circ} \mathrm{C}$. Lungs were removed and rinsed with

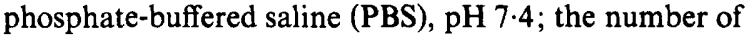

$P$. aeruginosa (cfu) was estimated by blending the lungs in $30 \mathrm{ml}$ of PBS and plating on nutrient agar. Approximately $10^{8} \mathrm{cfu} / \mathrm{ml}$ of homogenate were recovered.

\section{Recovery of bacteria grown in vivo from animal lungs}

Lung cell debris was removed from the tissue homogenate by coarse filtration through Whatman ashless filter paper. Material retained by the filter was washed twice with saline and the filter washings added to the bulked filtrate. The bacteria were harvested by a series of fast $(8000 \mathrm{~g})$ and slow $(3000 \mathrm{~g}) 10$-min centrifugations until light microscopy showed that the pellet consisted mainly of bacteria with some lung cell debris. The pellet was resuspended in $10 \mathrm{ml}$ of distilled water and outer membranes (OMs) prepared by Sarkosyl extraction as described below.

\section{Preparation of antisera}

Whole cells of strain PAO 579 grown to early stationary phase in TSB - Fe were harvested by centrifugation at $8000 \mathrm{~g}$ for $10 \mathrm{~min}$, washed twice in pyrogen-free normal saline, and resuspended to a density of approximately $10^{9}$ cells $/ \mathrm{ml}$ (optical density at $470 \mathrm{~nm} 1 \cdot 0$ ). The cells were fixed by addition of formalin (final concentration $4 \% \mathrm{v} / \mathrm{v}$ ). Male rats were immunised intraperitoneally at 2- and 3-day intervals in turn for 2 weeks. Blood samples were obtained by cardiac puncture and serum stored at $-20^{\circ} \mathrm{C}$. Blood was also obtained from a group of nonimmunised rats; serum was collected and stored at $-20^{\circ} \mathrm{C}$.

\section{Patients'sera}

Blood was obtained by venepuncture from $\mathrm{CF}$ patients who had been admitted to hospital with acute exacerbations of pulmonary infection. Serum was collected and stored at $-20^{\circ} \mathrm{C}$.

\section{Outer-membrane preparation and sodium dodecylsulphatè-polyacrylamide gel electrophoresis (SDS-PAGE)}

The bacterial pellet was resuspended in $20 \mathrm{ml}$ of distilled water and broken by $8 \times 30$-s pulses of sonication with 30-s intervals for cooling. Sodium lauryl sarcosinate (Sarkosyl: Sigma) was added to a final concentration of $2 \% \mathrm{w} / \mathrm{v}$. After incubation at room temperature for $60 \mathrm{~min}$, unbroken cells were removed by centrifugation at $8000 \mathrm{~g}$ for $10 \mathrm{~min}$. The outer membrane (OM) fragments were pelleted by centrifugation at $38000 \mathrm{~g}$ for $30 \mathrm{~min}$. The pellet was washed once with distilled water and then resuspended in $1 \mathrm{ml}$ of water and stored at $-20^{\circ} \mathrm{C}$. The protein concentration of each preparation was determined by the method of Lowry et al. (1951). Samples were adjusted to a protein concentration of $2 \mathrm{mg} / \mathrm{ml}$ and equal volumes were subjected to SDS-PAGE according to the system of Lugtenberg et al. (1975) as modified by 
Anwar et al. (1983) with purified SDS (specially purified; $\mathrm{BDH}$, Poole). Mol. wts of the OM proteins (OMPs) were assigned by comparison with the migration of standard proteins, i.e. $\beta$-galactosidase $\left(116 \times 10^{3}\right)$, phosphorylase b $\left(94 \times 10^{3}\right)$, bovine serum albumin $\left(67 \times 10^{3}\right)$, ovalbumin $\left(43 \times 10^{3}\right)$, carbonic anhydrase $\left(30 \times 10^{3}\right)$, trypsin inhibitor $\left(20 \times 10^{3}\right)$, and lysozyme $\left(14 \times 10^{3}\right)($ Sigma $)$ Gels $(14 \%$ acrylamide) were stained with Coomassie blue and scanned with a laser scanner. Protein antigens were identified on immunoblots by comparison with replicate strips of nitrocellulose containing $\mathrm{OM}$ samples and standard proteins.

\section{Immunoblotting}

OM antigens separated in acrylamide gels were transferred electrophoretically to nitrocellulose paper and antigenic sites visualised by a modification of the method of Towbin et al. (1979). The nitrocellulose was incubated with $10 \mathrm{mM}$ Tris $\mathrm{HCl}$, saline $0.85 \%, \mathrm{pH} 7.4$ (TBS) containing Tween $200.15 \% \mathrm{w} / \mathrm{v}$ (TBS/Tween) to saturate non-specific binding sites. This was followed by incubation with serum diluted 1 in 50 in TBS/Tween for $4 \mathrm{~h}$ at $37^{\circ} \mathrm{C}$. The nitrocellulose was then washed thoroughly with TBS. Antigens recognised by IgG antibodies in sera from patients or rats were revealed by incubation with horseradish peroxidase-conjugated rabbit anti-human IgG or rabbit anti-rat IgG (Miles Scientific, Rehovot, Israel) respectively, diluted 1 in 2000 in TBS/Tween. The nitrocellulose was washed thoroughly and visualised with a solution containing 4-chloro-1-naphthol $25 \mu \mathrm{g} / \mathrm{ml}$ and $\mathrm{H}_{2} \mathrm{O}_{2} 0.1 \% \mathrm{v} / \mathrm{v}$ in TBS. Directly after electrophoretic transfer of the OM antigens, portions of the nitrocellulose were stained with amido black $1 \% \mathrm{v} / \mathrm{v}$ in methanol $10 \%$ $\mathrm{v} / \mathrm{v}$ and acetic acid $7 \% \mathrm{v} / \mathrm{v}$.

\section{Absorption of serum antibodies to lipopolysaccharide (LPS)}

Early stationary phase cells of strain PAO 579 grown in TSB - Fe were harvested and LPS was extracted by the hot aqueous-phenol procedure of Westphal and Jann (1965). The absence of nucleic acids and protein contaminants in the purified product was confirmed by the absence of UV absorption at $260 \mathrm{~nm}$ and $280 \mathrm{~nm}$. To avoid detection of seeming protein antigens due to comigrating LPS, LPS-specific antibodies in sera from infected and immunised rats were absorbed by the method of Borowski et al. (1984) before use in immunoblotting.

\section{Results}

SDS-PAGE analysis of OMPs of strain PAO 579 grown in vivo

Fig. 1 shows the OMP profile of strain PAO 579 recovered directly from the lungs of infected rats

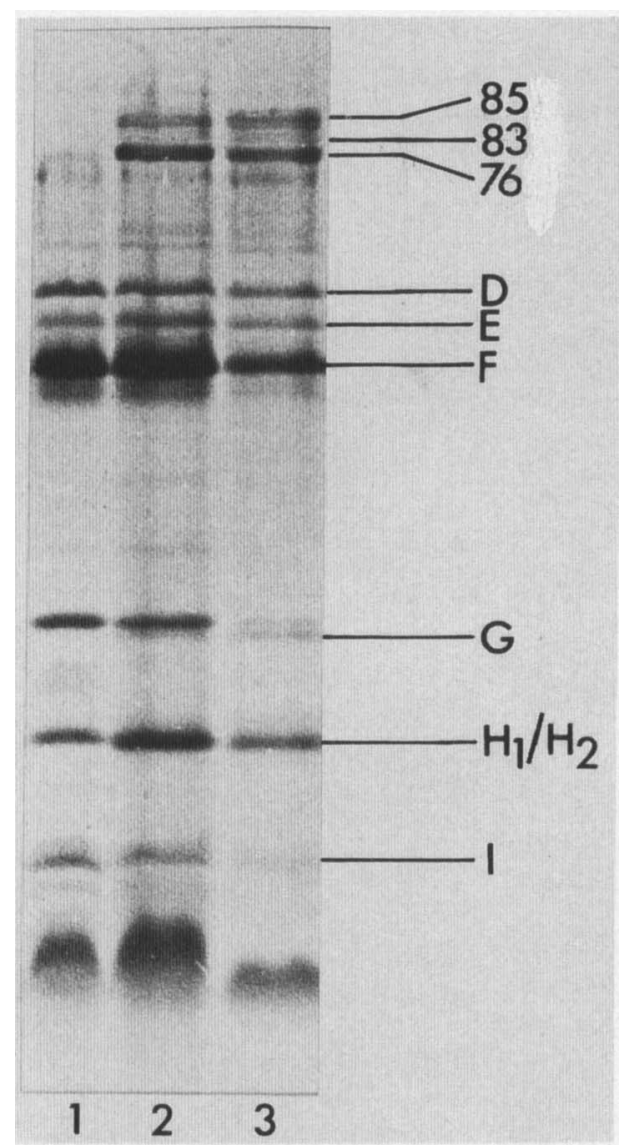

Fig. 1. The OMP profiles of mucoid P. aeruginosa PAO 579 isolated directly from the lungs of experimentally infected rats (lane 3) and of the same isolate cultivated in TSB - Fe (lane 2) and TSB + Fe (lane 1) laboratory media. Proteins were visualised by Coomassie blue staining. Letters in the right margin represent the OMPs of $P$. aeruginosa labelled according to standard nomenclature. The mol. wts $\left(10^{3}\right)$ of the IRMPs-76, 83 and 85 -are indicated.

(lane 3) and the same isolate grown in TSB - Fe (lane 2) and TSB + Fe (lane 1) laboratory media. Three proteins with mol. wts $\left(10^{3}\right) 76,83$ and 85 were strongly expressed in the OM of strain PAO 579 grown in vivo. Two further proteins with mol. wts $\left(10^{3}\right)$ c. 90 and c. 100, not revealed by Coomassie blue staining, were faintly seen after electrophoretic transfer of the OM antigens to nitrocellulose paper and staining with amido black $1 \% \mathrm{w} / \mathrm{v}$ (fig. 2). All of these proteins were expressed when the isolate was cultivated in TSB - Fe but not when TSB + Fe was used as the growth medium and are, therefore, termed IRMPs.

OMPs $G$ and I were expressed less in OMs prepared from strain PAO 579 grown in vivo than in OMs prepared from in-vitro cultures. The 


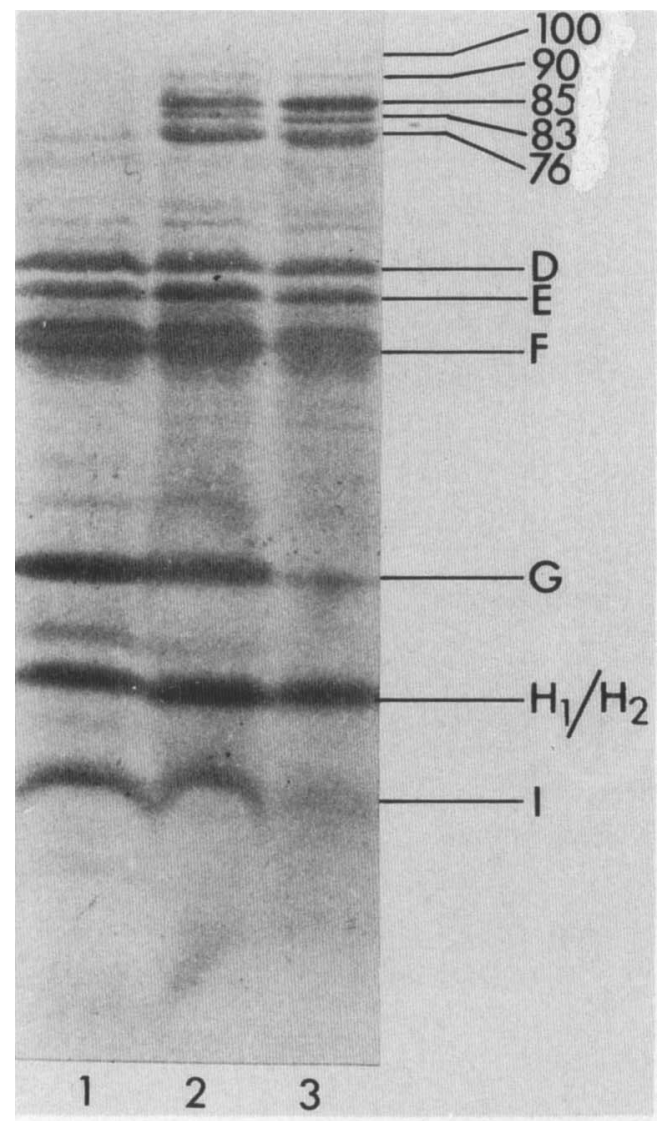

Fig. 2. Amido black stain of the OMPs shown in fig. 1 after electrophoretic transfer to nitrocellulose paper. Two further high-mol.-wt proteins of 90 and $100\left(10^{3}\right)$, which were not visualised by Coomassie blue staining, were seen.

expression of other major OMPs-D, E, F and H1/ $\mathrm{H} 2$ - as revealed by Coomassie blue staining, appeared to be similar in all the OM preparations studied. Complete transfer of all these proteins to nitrocellulose paper was confirmed by staining portions of the nitrocellulose with amido black $1 \%$ w/v (fig. 2) and the gel with Coomassie blue after transfer. Several bands that migrated to positions between proteins $F$ and $G$ were faintly visualised by staining with dyes in the OMs prepared from strain PAO 579 grown in vivo (fig. 2) and also in TSB - Fe (figs. 1 and 2). These bands were visualised much more faintly, or not at all, in OMs prepared from strain PAO 579 grown in $\mathrm{TSB}+\mathrm{Fe}$ (figs. 1 and 2). The electrophoretic mobility of OMP G is affected by heat and the concentration of 2-mercaptoethanol in the sample buffer (Hancock and Carey, 1979). A portion of this protein migrated with an apparent mol. wt of $23 \times 10^{3}$ and was visualised by amido black staining, migrating just above proteins $\mathrm{H} 1 / \mathrm{H} 2$ on this occasion (fig. 3).

\section{Antibody response to OMPs of strain PAO 579}

Sera obtained from chronically infected rats, 14 days after infection, were absorbed with LPS extracted from strain PAO 579. The presence of IgG to OMPs was investigated by immunoblotting techniques. An antibody response was elicited to $P$. aeruginosa major OMPs, including the IRMPs of mol. wts $\left(10^{3}\right) 76,83$ and 85 (fig. 3). The IRMP of mol. wt $76 \times 10^{3}$ was particularly strongly recognised by $\mathrm{IgG}$ in the sera from infected rats. These antibodies reacted with the IRMP of mol. wt $83 \times 10^{3}$ in the OM of strain PAO 579 grown in vivo but not when it had been cultivated in

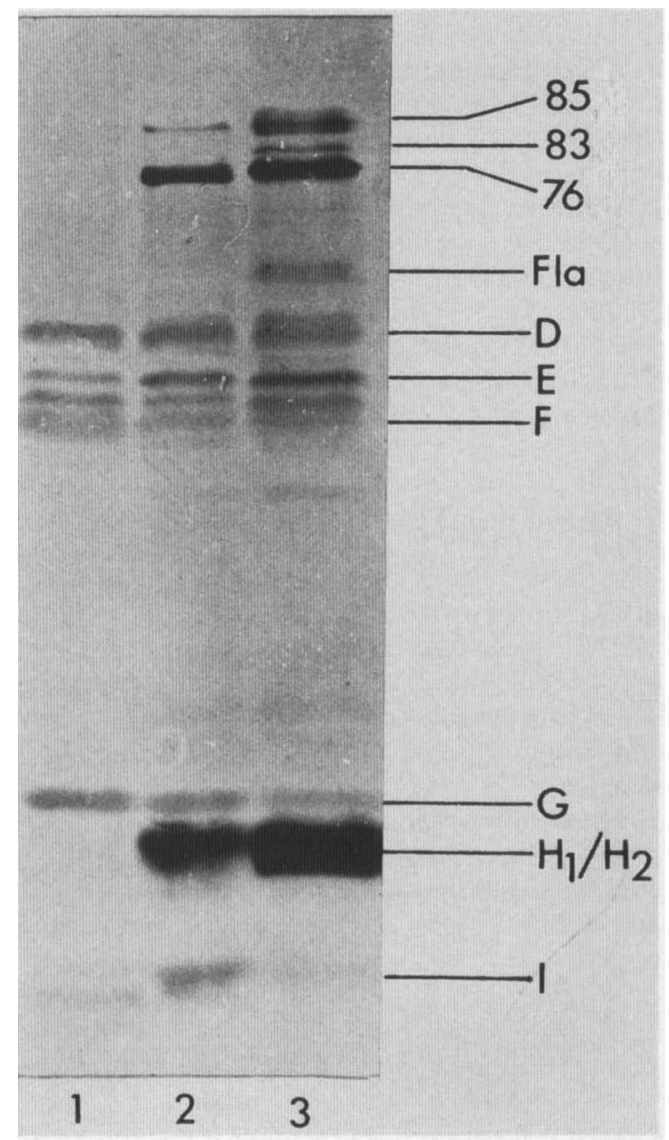

Fig. 3. Immunoblot of the OMPs shown in fig. 1 transferred electrophoretically to nitrocellulose paper and allowed to react with LPS-absorbed sera from infected rats. Peroxidase-labelled rabbit anti-rat IgG was used as the second antibody. 
TSB $-\mathrm{Fe}$. The reason for this is not clear. Differences noted in the reaction with the IRMPs associated with strain PAO 579 cells grown in vivo and in vitro may be due to greater amounts of these proteins being present in the OM of cells grown in vivo. An antigen with an estimated mol. wt of $54 \times$ $10^{3}$ in the OM of cells grown in vivo (lane 3 ), which was not visualised by Coomassie blue staining, was immunogenic. Flagellin protein prepared from strain PAO 579 co-migrated in SDS-PAGE with this band and IgG in sera from infected rats reacted with this antigen. The mol. wt of the OM antigen described here is closely similar to that assigned to purified flagellins from $P$. aeruginos $a$ type-b strains by other workers who used SDS-PAGE techniques (Allison et al., 1985). Thus, this antigen is probably flagellin protein. Although OMP G was present in much lower amounts in the OM of $P$. aeruginosa recovered directly from the lungs of infected rats, immunoblotting revealed the presence of $\mathrm{IgG}$ antibodies to this OM antigen in sera. Proteins $\mathrm{H} 1 /$ $\mathrm{H} 2$ in the $\mathrm{OM}$ of $P$. aeruginosa grown in vivo and in $\mathrm{TSB}-\mathrm{Fe}$ were recognised strongly by serum IgG (fig. 3, lanes 2 and 3). However, there was only a faint reaction with these antigens in the OM of $P$. aeruginosa cultivated in TSB + Fe (lane 1).

Sera from teenage CF patients with $P$. aeruginosa lung infection were also used in immunoblotting experiments. Fig. 4 shows that serum from one of these patients contained IgG which reacted with all the major OMPs of strain PAO 579. The reaction with the IRMPs was less strong than that seen when sera from infected rats was used in immunoblotting. Again, antibodies in serum reacted only faintly with proteins $\mathrm{H} 1$ and $\mathrm{H} 2$ in the $\mathrm{OM}$ of strain PAO 579 grown in TSB + Fe. Sera from other CF patients with chronic $P$. aeruginosa lung infection were also allowed to react with strain PAO 579 OM antigens. In all cases, much stronger reactions towards proteins $\mathrm{F}$ and $\mathrm{I}$ and a fast migrating band presumed to be core LPS were obtained with sera from $C F$ patients than with sera from infected rats (data not shown). The patients' sera had not been absorbed with extracted LPS as these patients' lungs were infected with non-typable strains of $P$. aeruginosa.

Immunoblotting of sera from a group of control teenage patients and from rats whose lungs had not been colonised with $P$. aeruginosa did not show IgG antibodies to the OMPs of $P$. aeruginosa. On the other hand, antisera from rats immunised with $P$. aeruginosa grown in iron-restricted conditions contained antibodies which reacted with all the major OMPs of strain PAO 579 including the IRMPs (data not shown).

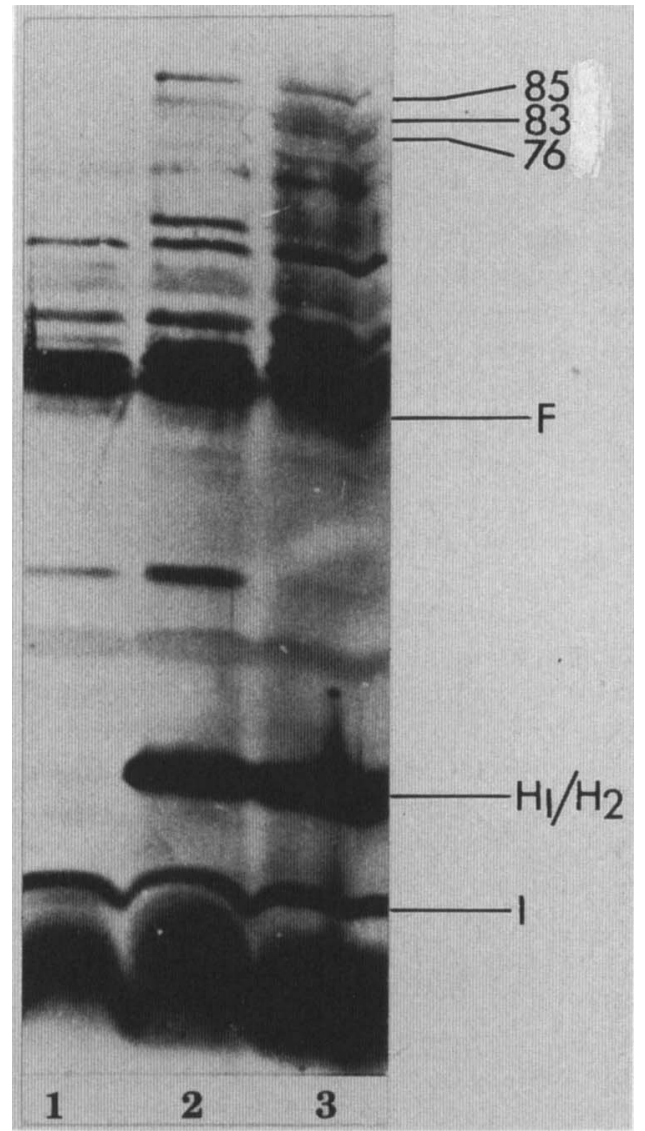

Fig. 4. Immunoblot of the OMPs shown in fig. 1 transferred electrophoretically to nitrocellulose paper and allowed to react with whole serum from a teenage CF patient with $P$. aeruginosa lung infection. Peroxidase labelled goat anti-human IgG was used as the second antibody.

\section{Discussion}

The surface components of bacteria play an important role in pathogenicity (Smith, 1977) and the expression of these components is influenced by the environment in which the bacteria grow (Ellwood and Tempest, 1972; Brown and Williams, 1985). The results of this study clearly indicated that $P$. aeruginosa grew under iron-restricted conditions in the lungs of experimentally infected rats, as judged by the expression of several IRMPs and the development of antibodies to these proteins. The pattern of IRMPs was similar to that obtained with $P$. aeruginosa taken directly from the sputum of a CF patient (Anwar et al., 1984; Brown et al., 1984). The same IRMPs were induced when the isolate used in this study was cultivated in vitro in iron-depleted media. However, OMP G was ex- 
pressed more strongly in the OM of cells grown in vitro than in those grown in vivo. The function of this protein has not been described. Features associated with the lung environment such as restriction of nutrients other than iron, oxygen tension, $\mathrm{pH}$, growth rate or the microcolony mode of growth are not mimicked by growth in vitro in iron-depleted broth. Furthermore, several bands that migrated to positions between proteins $F$ and $\mathrm{G}$ were faintly visualised by staining in the $\mathrm{OM}$ of cells grown in vivo and in iron-depleted media but not in OMs prepared from cells grown in ironplentiful media. The effect of growth environment on the expression of these bands is not clear.

The iron-binding proteins transferrin and lactoferrin have been identified in lung secretions (Reynolds and Chrétien, 1984). The effect of bacterial challenge on the amount of iron-binding proteins in the lung fluid of mice has recently been studied by LaForce et al. (1986), who showed that pulmonary challenge with aerosolised Escherichia coli resulted in a decrease in the levels of lactoferrin in the lung during the first hour followed by a rapid increase during the next $24 \mathrm{~h}$ so that lactoferrin became the predominant iron-binding protein in the lung fluid. The iron-binding proteins can have a powerful inhibitory effect on bacterial growth by restricting the availability of this essential nutrient (Weinberg, 1978; Bullen, 1981; Weinberg, 1984). Bacteria resist the bacteriostatic activity of ironbinding proteins through production of siderophores and the induction of OMPs that act as receptors for iron-siderophore complexes (Neilands, 1974; Griffiths, 1983). The role of the IRMPs reported in this study in the acquisition of iron has not been elucidated and clearly awaits further investigation. A low-mol.-wt $\left(14 \times 10^{3}\right)$ OMP involved in the uptake of ferripyochelin has been reported (Sokol and Woods, 1983; Sokol, 1984). We did not find any evidence for this protein in the present study. Indeed the antibody responses to the high-mol.-wt IRMPs reported here have been demonstrated in acute phase serum from an infected burn patient (Anwar et al., 1985) and serum from a CF patient (Anwar et al., 1984). The iron uptake

\section{REFERENCES}

Allison J S, Dawson M, Drake D, Montie T C 1985 Electrophoretic separation and molecular weight characterization of Pseudomonas aeruginosa $\mathrm{H}$-antigen flagellins. Infection and Immunity 49: 770-774.

Anwar H, Lambert P A, Brown M R W 1983 Influence of sodium dodecyl sulphate quality on the electrophoretic mobility of the outer membrane proteins of mucoid and system provides a potential target for immunological intervention in infections caused by $P$. aeruginosa.

$P$. aeruginosa isolated directly from the sputum of a CF patient contained elevated levels of OMP H1 (Brown et al., 1984). The patient had been receiving intravenous tobramycin and piperacillin. It was thought that induction of this protein might result from competition between the aminoglycoside tobramycin and metal cations for anionic cellsurface sites normally occupied by divalent cations (Brown et al., 1984). We have subsequently altered the gel system used in this study to allow separation of OMPs $\mathrm{H} 1$ and $\mathrm{H} 2$. The results indicate that protein $\mathrm{H} 1$ was induced in the $\mathrm{OM}$ of $P$. aeruginosa grown in vivo in the lungs of infected rats and was recognised by antibodies in the sera from infected animals and CF patients. Magnesium-depletion induces this protein (Nicas and Hancock, 1980; Anwar et al., 1983) and the lung may provide a magnesium-deficient environment for bacteria. We have investigated extensively the effect of irondepletion on the expression of proteins $\mathrm{H} 1$ and $\mathrm{H} 2$. The expression of these proteins is not affected by the iron content of the medium. The differences in the antibody response to these proteins in the OM of $P$. aeruginosa grown in vivo and in TSB-Fe compared with the response to cells grown in TSB + $\mathrm{Fe}$ may be due to differences in the antigenic determinants produced on proteins $\mathrm{H} 1$ and $\mathrm{H} 2$ in these growth conditions. Nutrients other than iron may be restricted in vivo in infection.

Overall, the results of this study suggest that the conditions of iron-deprivation which occur in human CF lung infection were simulated in this experimental model of the infection. We conclude that this animal model could be used to study the antibody response to $P$. aeruginosa in chronic lung infection.

This work was supported by a grant from the Cystic Fibrosis Research Trust (UK) and in part by a grant from the Medical Research Council (UK), both of which are gratefully acknowledged.

non-mucoid Pseudomonas aeruginosa. Biochimica et Biophysica Acta 761 : 119-125.

Anwar H, Brown M R W, Day A, Weller P H 1984 Outer membrane antigens of mucoid Pseudomonas aeruginosa isolated directly from the sputum of a cystic fibrosis patient. FEMS Microbiology Letters 24: 235-239.

Anwar H, Shand G H, Ward K H, Brown M R W, Alpar K E, Gowar J 1985 Antibody response to acute Pseudomonas aeruginosa infection in a burn wound. FEMS Microbiology Letters 29: 225-230. 
Borowski R S, Stock L M, Schiller N L 1984 Development of an enzyme-linked immunosorbent assay for studying Pseudomonas aeruginosa cell surface antigens. Journal of Clinical Microbiology 19: 736-741

Brown M R W, Anwar H, Lambert P A 1984 Evidence that mucoid Pseudomonas aeruginosa in the cystic fibrosis lung grows under iron-restricted conditions. FEMS Microbiology Letters 21 : 113-117.

Brown M R W, Williams P 1985 The influence of environment on envelope properties affecting survival of bacteria in infections. Annual Review of Microbiology 39: 527-556.

Bullen J J 1981 The significance of iron in infection. Reviews of Infectious Diseases 3: 1127-1137.

Cash H A, Woods D E, McCullough B, Johanson W G, Bass J A 1979 A rat model of chronic respiratory infection with Pseudomonas aeruginosa. American Review of Respiratory Disease 119: 453-459.

Costerton J W 1984 The etiology and persistence of cryptic bacterial infections: a hypothesis. Reviews of Infectious Diseases 6: S608-S616.

Doggett R G, Harrison G M, Stillwell R N, Wallis E S 1966 An atypical Pseudomonas aeruginosa associated with cystic fibrosis of the pancreas. Journal of Pediatrics 68: 215-221.

Ellwood D C, Tempest D W 1972 Effect of environment on bacterial wall content and composition. Advances in Microbial Physiology 114: 83-117.

Finkelstein R A, Sciortino C V, McIntosh M A 1983 Role of iron in microbe-host interactions. Reviews of Infectious Diseases 5: S759-777.

Griffiths E 1983 Availability of iron and survival of bacteria in infection. In: Easmon C S F et al. (eds) Medical microbiology, vol. 3. Role of the envelope in the survival of bacteria in infection. Academic Press, London, pp 153-177.

Griffiths E, Stevenson P, Joyce P 1983 Pathogenic Escherichia coli express new outer membrane proteins when growing in vivo. FEMS Microbiology Letters 16: 95-99.

Hancock R E W, Carey A M 1979 Outer membrane of Pseudomonas aeruginosa: heat- and 2-mercaptoethanolmodifiable proteins. Journal of Bacteriology 140: 902-910.

Høiby N 1974 Pseudomonas aeruginosa infection in cystic fibrosis. Relationship between mucoid strains of Pseudomonal aeruginosa and the humoral immune response. Acta Pathologica Microbiologica et Immunologica Scandinavica Section B 82: $551-558$.

Kadurugamuwa J L, Anwar H, Brown M R W, Shand G H, Ward K H 1987 Media for study of growth kinetics and envelope properties of iron-deprived bacteria. Journal of Clinical Microbiology 25 : 849-855.

LaForce F M, Boose D S, Ellison R T 1986 Effect of aerosolized Escherichia coli and Staphylococcus aureus on iron and ironbinding proteins in lung lavage fluid. Journal of Infectious Diseases 154: 959-965.
Lam J, Chan R, Lam K, Costerton J W 1980 Production of mucoid microcolonies by Pseudomonas aeruginosa within infected lungs in cystic fibrosis. Infection and Immunity 28 : 546-556.

Lam C, Turnowsky F, Schwarzinger E, Neruda W 1984 Bacteria recovered without subculture from infected human urines express iron-regulated membrane proteins. FEMS Microbiology Letters 24 : 255-259.

Lowry O H, Rosebrough N J, Farr A J, Randall R J 1951 Protein measurement with folin phenol reagent. Journal of Biological Chemistry 193: 265-275.

Lugtenberg B, Meijers J, Peters R, van der Hoek P, van Alphen L 1975 Electrophoretic resolution of the "major outer membrane protein" of Escherichia coli K-12 into four bands. FEBS Letters 58: 254-258.

Neilands J B 1974 Iron and its role in microbial physiology. In : Neilands J B (ed) Microbial iron metabolism. Academic Press Inc., New York, pp 4-34.

Nicas T I, Hancock R E W 1980 Outer membrane protein H1 of Pseudomonas aeruginosa: involvement in adaptive and mutational resistance to ethylene-diamine tetraacetate, polymyxin B and gentamicin. Journal of Bacteriology 143: 872-878.

Reynolds N Y, Chrétien J 1984 Respiratory tract fluids. Analysis of content and contemporary use in understanding lung diseases. Disease-a-month (Year book) 30 : 1-103.

Sciortino C V, Finkelstein R A 1983 Vibrio cholerae expresses iron-regulated outer membrane proteins in vivo. Infection and Immunity 42: 990-996.

Shand G H, Anwar H, Kadurugamuwa J, Brown M R W, Silverman S H, Melling J 1985 In vivo evidence that bacteria in urinary tract infection grow under iron-restricted conditions. Infection and Immunity 48: 35-39.

Smith H 1977 Microbial surfaces in relation to pathogenicity. Bacteriological Reviews 41 : 475-500.

Sokol P A 1984 Production of the ferripyochelin outer membrane receptor by Pseudomonas species. FEMS Microbiology Letters 23: 313-317.

Sokol P A, Woods D E 1983 Demonstration of an iron siderophore-binding protein in the outer membrane of Pseudomonas aeruginosa. Infection and Immunity 40: 665669.

Towbin H, Staehelin J, Gordon J 1979 Electrophoretic transfer of proteins from polyacrylamide gels to nitrocellulose sheets: procedure and some applications. Proceedings of the National Academy of Sciences of the USA. 76: 4350-4354.

Weinberg E D 1978 Iron and infection. Microbiological Reviews 42: 45-66.

Weinberg E D 1984 Iron withholding: a defence against infection and neoplasia. Physiological Reviews 64: 65-102.

Westphal O, Jann K 1965 Bacterial lipopolysaccharides. Extraction with phenol-water and further applications of the procedure. Methods in Carbohydrate Chemistry 5: 8391. 